\title{
Methamphetamine treatment during development attenuates the dopaminergic deficits caused by subsequent high-dose methamphetamine administration
}

\author{
Lisa M McFadden, Amanda J Hoonakker, Paula L Vieira-Brock, Kristen A Stout, Nicole M \\ Sawada, Jonathan D Ellis, Scott C Allen, Elliot T Walters, Shannon M Nielsen, James W \\ Gibb, Mario E Alburges, Diana G Wilkins, Glen R Hanson, and Annette E Fleckenstein \\ Department of Pharmacology and Toxicology, University of Utah, Salt Lake City, UT 84112
}

\begin{abstract}
Administration of high doses of methamphetamine (METH) causes persistent dopaminergic deficits in both nonhuman preclinical models and METH-dependent persons. Noteworthy, adolescent (i.e., postnatal day (PND) 40) rats are less susceptible to this damage than young adult (PND90) rats. In addition, biweekly treatment with METH, beginning at PND40 and continuing throughout development, prevents the persistent dopaminergic deficits caused by a "challenge" high-dose METH regimen when administered at PND90. Mechanisms underlying this "resistance" were thus investigated. Results revealed that biweekly METH treatment throughout development attenuated both the acute and persistent deficits in VMAT2 function, as well as the acute hyperthermia, caused by a challenge METH treatment. Pharmacokinetic alterations did not appear to contribute to the protection afforded by the biweekly treatment. Maintenance of METH-induced hyperthermia abolished the protection against both the acute and persistent VMAT2-associated deficits suggesting that alterations in thermoregulation were caused by exposure of rats to METH during development. These findings suggest METH during development prevents METH-induced hyperthermia and the consequent METH-related neurotoxicity.
\end{abstract}

\section{Keywords}

Methamphetamine; Vesicular Monoamine Transporter-2; Adolescence

\section{Introduction}

In $2009,1.6$ and $2.8 \%$ of $8^{\text {th }}$ and $10^{\text {th }}$ graders in the United States, respectively, had used methamphetamine (METH) illicitly (Johnston et al., 2010). This is of concern, since highdose METH administration causes persistent reductions in striatal dopamine content, dopamine transporter density, and activity of the dopamine synthesizing enzyme, tyrosine hydroxylase, in rodents (Hotchkiss et al., 1979; Wagner et al., 1980; Guilarte et al., 2003) non-human primates (Woolverton et al., 1989) and/or humans (Wilson et al., 1996; McCann et al., 1998; Sekine et al., 2001; Volkow et al., 2001). Mechanisms contributing to these dopaminergic deficits and their consequences remain a focus of study (for review, see Yamamoto and Bankson, 2005; Calabrese, 2008; Krasnova \& Cadet, 2009; Hanson and Fleckenstein, 2009). The potential clinical relevance of understanding mechanisms underlying these deficits is underscored by findings that METH abusers often display impairment across several neurocognitive domains, including deficits in executive function

Corresponding Author: Lisa M. McFadden, Department of Pharmacology and Toxicology, University of Utah, Salt Lake City, UT 84121, Telephone: 801-585-7474, Fax: 801-585-5111, lisa.mcfadden@utah.edu. 
and memory (Gonzalez et al., 2007; Volkow et al., 2001; Simon et al., 2000; Kalechstein et al., 2003; Scott et al., 2007). At least some METH-induced cognitive deficits appear to correlate with dopaminergic impairments (Belcher et al., 2008; Daberkow et al., 2005; Volkow et al., 2001).

Most studies of METH or other amphetamine analogs have utilized adult animal models. However, given the prevalence of METH use among young people, it is important to elucidate effects of METH in adolescent models. Accordingly, studies have focused on the impact of stimulant treatment during adolescence (for review, see Andersen, 2005). For example, Unterwald and colleagues reported that chronic amphetamine treatment upregulates FosB in the nucleus accumbens of periadolescent, but not adult, mice (Erlich et al., 2002). Vorhees et al. (2005) reported that periadolescent rats are particularly sensitive to METH-induced sequential and spatial learning deficits compared to adult rats. Further, Brunell and Spear (2006) reported that high-dose amphetamine treatment disrupts pre-pulse inhibition in adult, but not adolescent, animals.

Of relevance to the present study, high-dose METH treatment reduces striatal dopamine levels in PND60, but not PND20, rats (Cappon et al., 1997). Similarly, METH causes a loss of tyrosine hydroxylase-positive terminals in PND60 and PND80 rats, but not PND40 and younger rats (Pu and Vorhees, 1993). Additionally, high-dose METH treatment causes longterm decreases in dopamine transporter activity, tyrosine hydroxylase activity, and binding of the dopamine transporter ligand, WIN35428, in PND90, but not PND40, rats (Kokoshka et al., 2000).

Although studies described above indicate that younger rodents are less susceptible to METH-induced dopaminergic deficits than older animals, these reports do not address whether METH administration to younger animals alters the pattern of response when exposed in adulthood. To this end, Riddle et al. (2002) reported that high-dose METH administration decreases striatal dopamine uptake and dopamine transporter ligand binding in PND90 rats as assessed $7 \mathrm{~d}$ after treatment, effects that were blocked if animals received six biweekly METH pretreatments beginning at PND40. Both the ability of biweekly pretreatment to alter acute effects of METH and mechanisms underlying this 7-d neuroprotection phenomenon remain to be elucidated. Accordingly, the purpose of this study was to extend previous research to find underlying mechanisms behind this protection.

\section{Materials and Methods}

\subsection{Animals}

Male Sprague Dawley rats (PND40-PND90; Charles River, Raleigh NC) were grouphoused initially at 4-5 per cage but were reassigned to 3 per cage in accordance with IACUC standards with an alternating light/dark cycle (lights on $14 \mathrm{~h} /$ day). Food and water were provided ad libitum. According to endocrine markers of sexual maturity, PND40 and PND90 rats correlate with early puberty (or adolescence) and early adulthood in animals, respectively (Ojeda et al., 1980, 1994). Rats were sacrificed by decapitation. All animals were treated in accordance with the NIH Guide for the Care and Use of Laboratory Animals.

\subsection{Injections}

Beginning at PND 40, rats received two biweekly injections (s.c.) of either saline ( $1 \mathrm{ml} / \mathrm{kg} /$ injection) or METH ( $7.5 \mathrm{mg} / \mathrm{kg} /$ injection on consecutive days for 6 weeks) in an ambient environmental temperature of $23^{\circ} \mathrm{C}$. On PD90, rats received either a "binge" METH treatment $(4 \times 7.5 \mathrm{mg} / \mathrm{kg} /$ injection, 2 -h intervals, s.c.) or saline $(1 \mathrm{ml} / \mathrm{kg} /$ injection, 2 -h intervals, s.c.). Where indicated, core body (rectal) temperatures were measured using a digital thermometer (Physiotemp Instruments, Clifton, NJ) 30 min prior to the first drug 
treatment and every 30 or 60 min after each treatment with drug or saline. Rats received the binge METH treatment in ambient environments of $23^{\circ} \mathrm{C}$ and $25^{\circ} \mathrm{C}$ in experiments presented in Figs. 1 and 2, respectively. If an animal's core temperature reached $41^{\circ} \mathrm{C}$ during the METH binge treatment, rats were cooled until their core temperature reached $39.5^{\circ} \mathrm{C}$.

\subsection{Drugs and chemicals}

[7,8-3H]Dopamine (46 Ci/mmol) was purchased from Perkin Elmer (Boston, MA). Methamphetamine hydrochloride was furnished by the National Institute on Drug Abuse (Research Triangle Institute; Research Triangle Park, NC). Drugs were administered as indicated in figure legends and doses were calculated as the respective free bases.

\subsection{Vesicular [3H]DA uptake and methamphetamine/amphetamine concentrations}

Vesicular $[3 \mathrm{H}]$ dopamine $(0.5 \mathrm{nM}$ final concentration) uptake was determined as described previously (Sandoval et al., 2002; Truong et al., 2005; Hanson et al., 2009).

Methamphetamine concentrations were determined by gas chromotography coupled to mass spectroscopy as described previously (Truong et al., 2005).

\subsection{Statistics}

All statistical analyses were conducted in SAS 9.2 (Cary, NC, USA). Statistical analyses among groups for the uptake assays were conducted using analysis of variance (ANOVA), followed by Newman-Keuls posthoc analyses. Analysis of temperatures were conducted using a repeated measures ANOVA followed by Newman-Keuls posthoc analyses.

Violations of the sphericity assumption resulted in the use of a Huynh-Feldt correction. Differences among groups were considered significant if the probability of error was less than 5\%. The data represent means \pm standard error of the mean (S.E.M.) of each group which contained 6 animals.

\section{Results}

Results presented in Fig. 1 confirm that high-dose treatment with METH, administered in a pattern designed to mimic a "binge" treatment (referred to herein as a "challenge" METH treatment; $4 \times 7.5 \mathrm{mg} / \mathrm{kg} / \mathrm{injection}$, s.c., 2-h intervals), cause both acute and long-term dopaminergic deficits in PND90 as determined $1 \mathrm{~h}$ (Fig. 1A) or 7 days (Fig. 1C) after treatment by assessing striatal vesicular $[3 \mathrm{H}]$ dopamine uptake. These METH-induced dopaminergic deficits were attenuated if rats received biweekly METH treatments beginning at PND40. Specifically, rats received a single injection of METH $(7.5 \mathrm{mg} / \mathrm{kg}$, s.c.) on two consecutive days, and this biweekly treatment was repeated for six consecutive weeks. One week after the final treatment (i.e., at a time at which rats had attained the age PND90), rats received the "challenge" METH treatment. Rats were then decapitated $1 \mathrm{~h}$ or 7 days later, and striatal vesicular $\left[{ }^{3} \mathrm{H}\right]$ dopamine uptake was assessed. As demonstrated in Fig. 1, the binge treatment of METH decreased striatal $\left[{ }^{3} \mathrm{H}\right]$ dopamine uptake by approximately 51.8 and $71.7 \%$ in animals pretreated with saline as assessed $1 \mathrm{~h}$ or 7 days later, respectively. This effect was attenuated in rats that received the biweekly METH pretreatment regimen (1 h: $F(3,20)=11.71, p<0.05 ; 7$ days: $F(3,20)=17.64, p<0.05)$. Of note, biweekly METH pretreatment regiment did not lead to mortality during the METH challenge whereas $4.8 \%$ of rats that did not receive METH during adolescence succumbed to the challenge regimen.

To investigate the possibility that pharmacokinetics contributed to the neuroprotective effects of the biweekly METH pretreatment regimen, whole brain METH concentrations were assessed from rats. Results revealed that these values did not change as a result of the pretreatment regimen. Specifically, the respective mean whole brain concentrations of METH $1 \mathrm{~h}$ after binge treatment were $4.537 \mathrm{ng} / \mathrm{mg}$ tissue $(0.618$ S.E.M.) and $5.60 \mathrm{ng} / \mathrm{mg}$ 
tissue (0.451 S.E.M.) for the saline pretreated/ METH challenged rats and the METH pretreated/METH challenged rats respectively $(\mathrm{t}(10)=1.389$, ns). Results presented in Fig. 1 demonstrate that in addition to attenuating decreases in VMAT2 function, the biweekly pretreatment regimen with METH attenuated the METH-induced hyperthermia caused by the subsequent binge METH administration $(1 \mathrm{~h}: \mathrm{F}(12,80)=9.89$, $\mathrm{p}<0.05 ; 7$ days: $\mathrm{F}(12,80)=8.67$, p <0.05; Fig. 1B and 1D, respectively). However, when hyperthermia was maintained by administering the challenge regimen in a warm environment $\left(25^{\circ} \mathrm{C} ; 1 \mathrm{~h}\right.$ : $F(12,80)=14.30, p<0.05 ; 7$ days: $F(12,80)=14.22$, p $<0.05$; Fig. $2 B$ and $2 D$, respectively), the biweekly pretreatment was no longer protective against either the acute or persistent decrease in VMAT2 function (Fig. $2 ; 1$ h: $F(3,20)=20.63$, p <0.05; 7 days: $F(3,20)=10.81$, p $<0.05$; Fig. $2 \mathrm{~A}$ and $2 \mathrm{C}$, respectively). Maintaining hyperthermia by administering a METH challenge in a warm environment lead to similar mortality in both groups during the challenge (Saline-treated/METH challenged: 3.8\% mortality; METH-treated/METH challenged: $4.3 \%$ mortality).

\section{Discussion}

As noted above, high-dose METH administration decreases striatal dopamine uptake and transporter ligand binding in PND90 rats as assessed 7 days after treatment, effects that were attenuated if animals received six biweekly METH pretreatments beginning at PND40. The present study confirms these findings using a distinctly different marker of dopaminergic neuronal integrity: the VMAT2 (Darchen et al., 1989; Brown et al., 2000; Guilarte et al., 2003). In particular, biweekly METH treatment during adolescence was without effect per $s e$, but prevented the decrease in VMAT2 activity as assessed 7 days after a high-dose METH challenge. Biweekly treatment also attenuated the hyperthermic response to a challenge METH treatment. However, when the challenge METH treatment was administered in a warm environment such that hyperthermia was maintained in all METHpretreated rats, the protection afforded by the biweekly pretreatment was eliminated. These findings demonstrate the importance of hyperthermia and are consistent with previous findings that attenuation of hyperthermia per se, or as a consequence of antagonist pretreatment, attenuates both acute and persistent dopaminergic deficits caused by METH (Bowyer et al., 1993; Albers and Sonsalla, 1995; Farfel and Seiden, 1995; Fleckenstein et al., 1997; Metzger et al., 2000; Broening et al., 2005; Chu et al., 2008; Hadlock et al., 2009; Hadlock et al., submitted).

In addition to serving as a marker of dopaminergic neuronal integrity, deficits in VMAT2 function can contribute to the persistent dopaminergic deficits caused by the stimulant, as evidenced by findings that such deficits are worsened in heterozygous VMAT2 knockout mice (Fumagalli et al., 1999). Further, treatment with the VMAT2 inhibitor, reserpine, worsens the dopaminergic deficits caused by METH (Wagner et al., 1983; Thomas et al., 2008). Deficits in VMAT2 function likely promote abnormal intraneuronal dopamine accumulation that, in turn, promotes formation of intraneuronal dopamine-associated reactive species that contribute to the persistent dopaminergic deficits caused by METH (Cubells et al., 1994; for review, Fleckenstein et al., 2009).

Given the contribution of VMAT2 to the persistent dopaminergic deficits caused by METH, the impact of biweekly pretreatment of the stimulant was assessed. Results confirmed previous findings that a challenge METH treatment rapidly decreases the activity of this transporter, as assessed 1 hour after treatment in non-synaptosomal membrane-associated vesicles purified from treated rats (Brown et al., 2000; Sandoval et al., 2002). Biweekly METH treatment attenuated the acute decreases in the activity of this transporter following a METH challenge while having no effect on transport function following a saline challenge. Thus, these data are consistent with the premise that the acute deficits in VMAT2 function 
may contribute to the persistent dopaminergic deficits caused by the challenge METH administration.

Of interest are findings that when hyperthermia was maintained in METH-challenged rats, protection against the acute decrease in VMAT2 function was largely abolished. This protection is seemingly consistent with findings by Eyerman and Yamamoto (2005) in that prevention of METH-induced hyperthermia likewise prevents the acute decrease in VMAT2 immunoreactivity caused by a challenge administration of the stimulant. Thus, one interpretation of these data would be that as with the persistent deficits in VMAT2 function, hyperthermia contributes to the acute decreases, perhaps by promoting reactive species generation (Fleckenstein et al., 1997, LaVoie and Hastings, 1999). However, Johnson-Davis et al. (2004) demonstrated that prevention of METH-induced hyperthermia per se did not prevent the acute decrease in VMAT2 function caused by a high-dose METH regimen. This latter finding permits speculation that the attenuation of hyperthermia afforded by the biweekly treatment may not have contributed to protection against the acute deficits in VMAT2 function, and other mechanisms underlie this phenomenon.

Some studies suggest that pretreatment of rats with various dosing regimens of METH affords protection against its persistent monoaminergic deficits by altering the pharmacokinetics of the stimulant. For example, Gygi et al. (1996) demonstrated that an escalating dose regimen of METH affords neuroprotection against the serotonergic deficits caused by a subsequent METH challenge. Further, this escalating dose regimen also alters the brain/plasma METH ratio consequent to the challenge thereby indicating a role for pharmacokinetics (but see also O'Neil et al., 2006). In contrast, the present data support previous findings (Riddle et al., 2002) that brain METH concentrations did not differ between METH-challenged rats that received the biweekly pretreatment and those that did not. Although these data are limited in that METH levels were only assessed at a single time point and altered pharmacokinetics cannot be excluded absolutely, these results suggest that alterations in brain METH levels did not contribute to the neuroprotective effects afforded by the biweekly METH pretreatment.

In conclusion, the present findings reveal that treatment of METH during development attenuates the persistent dopaminergic deficits caused by the stimulant. Both an attenuation of hyperthermia and the loss of VMAT2 function likely contribute to this phenomenon. Future research will explore possible underlying mechanisms behind the attenuation of hyperthermia and VMAT2 deficits in the rats treated with METH throughout development by examining the role of D1 and 5HT2 receptors, receptors demonstrated to play a role in METH-induced hyperthermia (Doyle \& Yamamoto, 2010; Shioda et al., 2010). In addition, promoting METH-induced hyperthermia increases permeability of the blood-brain-barrier and thus promote brain edema, neuronal degeneration and glial cell damage (Bowyer \& Ali, 2006; Kiyatkin et al., 2007; Bowyer et al., 2008; Sharma \& Kiyatkin, 2009). The impact of METH treatment throughout development on these processes will also be an important future direction.

\section{Acknowledgments}

This work was supported by National Institutes of Health grants DA019447, DA013367, DA00869, DA11389, DA04222 and DA00378.

\section{References}

Albers DS, Sonsalla PK. Methamphetamine-induced hyperthermia and dopaminergic neurotoxicity in mice: pharmacological profile of protective and nonprotective agents. J Pharmacol Exp Ther. 1995; 275:1104-1114. [PubMed: 8531070] 
Andersen SL. Stimulants and the developing brain. Trends Pharmacol Sci. 2005; 26:237-243. [PubMed: 15860370]

Belcher AM, Feinstein EM, O'Dell SJ, Marshall JF. Methamphetamine influences on recognition memory: Comparison of escalating and single-day dosing regimens. Neuropsychopharm. 2008; 33:1453-1463.

Bowyer JF, Ali S. High doses of methamphetamine that cause disruption of the blood-brain barrier in limbic regions produce extensive neuronal degeneration in mouse hippocampus. Synapse. 2006; 60(7):521-32. [PubMed: 16952162]

Bowyer JF, Gough B, Slikker W Jr, Lipe GW, Newport GD, Holson RR. Effects of a cold environment or age on methamphetamine-induced dopamine release in the caudate putamen of female rats. Pharmacol Biochem Behav. 1993; 44:87-98. [PubMed: 8094252]

Bowyer JF, Robinson B, Ali S, Schmued LC. Neurotoxic-related changes in tyrosine hydroxylase, microglia, myelin, and the blood-brain barrier in the caudate-putamen from acute methamphetamine exposure. Synapse. 2008; 62(3):193-204. [PubMed: 18081184]

Broening HW, Morford LL, Vorhees CV. Interactions of dopamine D1 and D2 receptor antagonists with D-methamphetamine-induced hyperthermia and striatal dopamine and serotonin reductions. Synapse. 2005; 56:84-93. [PubMed: 15714503]

Brown JM, Hanson GR, Fleckenstein AE. Methamphetamine rapidly decreases vesicular dopamine uptake. J Neurochem. 2000; 74(5):2221-3. [PubMed: 10800970]

Brunell SC, Spear LP. Effects of acute ethanol or amphetamine administration on the acoustic startle response and prepulse inhibition in adolescent and adult rats. Psychopharmacology. 2006; 186(4): 579-86. [PubMed: 16758242]

Calabrese EJ. Pharmacological enhancement of neuronal survival. Crit Rev Toxicol. 2008; 38(4):34989. [PubMed: 18432420]

Cappon GD, Morford LL, Vorhees CV. Ontogeny of methamphetamine-induced neurotoxicity and associated hyperthermic response. Brain Res Dev Brain Res. 1997; 103:155-162.

Chu PW, Seferian KS, Birdsall E, Truong JG, Riordan JA, Metcalf CS, Hanson GR, Fleckenstein AE. Differential regional effects of methamphetamine on dopamine transport. Eur J Pharmacol. 2008; 590(1-3):105-10. [PubMed: 18599036]

Cubells JF, Rayport S, Rajendran G, Sulzer D. Methamphetamine neurotoxicity involves vacuolation of endocytic organelles and dopamine-dependent intracellular oxidative stress. J Neurosci. 1994; 14:2260-2271. [PubMed: 8158268]

Daberkow DP, Kesner RP, Keefe KA. Relation between methamphetamine-induced monoamine depletions in the striatum and sequential motor learning. Pharmacol Biochem Behav. 2005; 81:198-204. [PubMed: 15894079]

Darchen F, Masuo Y, Vial M, Rostene W, Scherman D. Quantitative autoradiography of the rat brain vesicular monoamine transporter using the binding of $[3 \mathrm{H}]$ dihydrotetrabenazine and 7-amino-8[125I]iodoketanserin. Neuroscience. 1989; 33:341-349. [PubMed: 2622531]

Doyle JR, Yamamoto BK. Serotonin 2 receptor modulation of hyperthermia, corticosterone, and hippocampal serotonin depletions following serial exposure to chronic stress and methamphetamine. Psychoneuroendocrinology. 2010; 35(4):629-33. [PubMed: 19879056]

Ehrlich ME, Sommer J, Canas E, Unterwald. Periadolescent mice show enhanced $\Delta$ fosB upregulation in response to cocaine and amphetamine. J Neurosci. 2002; 22:9155-9159. [PubMed: 12417638]

Eyerman DJ, Yamamoto BK. Lobeline attenuates methamphetamine-induced changes in vesicular monoamine transporter 2 immunoreactivity and monoamine depletions in the striatum. $\mathrm{J}$ Pharmacol Exp Ther. 2005; 312(1):160-9. [PubMed: 15331654]

Farfel GM, Seiden LS. Role of hypothermia in the mechanism of protection against serotonergic toxicity. II. Experiments with methamphetamine, p-chloroamphetamine, fenfluramine, dizocilpine and dextromethorphan. J Pharmacol Exp Ther. 1995; 272:868-875. [PubMed: 7853205]

Fleckenstein AE, Volz TJ, Hanson GR. Psychostimulant-induced alterations in vesicular monoamine transporter-2 function: Neurotoxic and therapeutic implications. Neuropharmacology. 2009; 56(Suppl 1):133-8. [PubMed: 18662707] 
Fleckenstein AE, Wilkins DG, Gibb JW, Hanson GR. Interaction between hyperthermia and oxygen radical formation in the 5-hydroxytryptaminergic response to a single methamphetamine administration. J Pharmacol Exp Ther. 1997; 283:281-5. [PubMed: 9336334]

Fumagalli F, Gainetdinov RR, Wang YM, Valenzano KJ, Miller GW, Caron MG. Increased methamphetamine neurotoxicity in heterozygous vesicular monoamine transporter 2 knock-out mice. J Neurosci. 1999; 19:2424-31. [PubMed: 10087057]

Gonzalez R, Bechara A, Martin EM. Executive functions among individuals with methamphetamine or alcohol as drugs of choice: preliminary observations. J Clin Exp Neuropsychol. 2007; 29:155-159. [PubMed: 17365250]

Guilarte TR, Nihei MK, McGlothan JL, Howard AS. Methamphetamine-induced deficits of brain monoaminergic neuronal markers: distal axotomy or neuronal plasticity. Neuroscience. 2003; 122:499-513. [PubMed: 14614914]

Gygi MP, Gygi SP, Johnson M, Wilkins DG, Gibb JW, Hanson GR. Mechanisms for tolerance to methamphetamine effects. Neuropharmacology. 1999; 35(6):751-7. [PubMed: 8887984]

Hadlock GC, Baucum AJ, King JL, Horner KA, Cook GA, Riordan JA, Gibb JW, Wilkins DG, Hanson GR, Fleckenstein AE. Mechanisms underlying methamphetamine-induced dopamine transporter complex formation. J Pharmacol Exp Ther. 2009; 329:169-74. [PubMed: 19141713]

Hadlock GC, Chu P-W, Walters ET, Hanson GR, Fleckenstein AE. Methamphetamine-induced dopamine transporter complex formation and dopaminergic deficits: The role of D2 receptor activation. J Pharmacol Exp Ther. 2010; 335(1):207-12. [PubMed: 20622144]

Hanson, GR.; Fleckenstein, AE. Methamphetamine Addiction: From Basic Science to Treatment. The Guilford Press; New York: 2009. Basic neuropharmacological mechanisms of methamphetamine.

Hanson JE, Birdsall E, Seferian KS, Crosby MA, Keefe KA, Gibb JW, Hanson GR, Fleckenstein AE. Methamphetamine-induced dopaminergic deficits and refractoriness to subsequent treatment. Eur J Pharmacol. 2009; 607:68-73. [PubMed: 19326567]

Hotchkiss A, Morgan ME, Gibb JW. The long-term effects of multiple doses of methamphetamine on neostriatal tryptophan hydroxlase, tyrosine hydroxylase, choline acetyltransferase and glutamate decarboxylase activities. Life Sci. 1979; 25:1373-1378. [PubMed: 42834]

Johnson-Davis KL, Truong JG, Fleckenstein AE, Wilkins DG. Alterations in vesicular dopamine uptake contribute to tolerance to the neurotoxic effects of methamphetamine. J Pharmacol Exp Ther. 2004; 309(2):578-86. [PubMed: 14747615]

Johnston LD, O'Malley PM, Bachman JG, Schulenberg JE. Trends in Lifetime Prevalence of Use of Various Drugs in Grades. 2009; 8:10, 12. Retrieved 7/01/2010 from http:// www.monitoringthefuture.org.

Kalechstein AD, Newton TF, Green M. Methamphetamine dependence is associated with neurocognitive impairment in the initial phases of abstinence. J Neuropsychiatry Clin Neurosci. 2003; 15:215-220. [PubMed: 12724464]

Kiyatkin EA, Brown PL, Sharma HS. Brain edema and breakdown of the blood-brain barrier during methamphetamine intoxication: critical role of brain hyperthermia. Eur J Neurosci. 2007; 26(5): 1242-53. [PubMed: 17767502]

Kokoshka JM, Fleckenstein AE, Wilkins DG, Hanson GR. Age-dependent differential responses of monoaminergic systems to high doses of methamphetamine. J Neurochem. 2000; 75:2095-2102. [PubMed: 11032899]

Krasnova IN, Cadet JL. Methamphetamine toxicity and messengers of death. Brain Res Rev. 2009; 60(2):379-407. [PubMed: 19328213]

LaVoie MJ, Hastings TG. Dopamine quinone formation and protein modification associated with the striatal neurotoxicity of methamphetamine: evidence against a role for extracellular dopamine. $\mathrm{J}$ Neurosci. 1999; 19(4):1484-91. [PubMed: 9952424]

McCann UD, Wong DF, Yokoi F, Villemagne V, Dannals RF, Ricaurte GA. Reduced striatal dopamine transporter density in abstinent methamphetamine and methcathinone users: evidence from positron emission tomography studies with [11C]WIN-35,428. J Neurosci. 1998; 18(20): 8417-22. [PubMed: 9763484] 
Metzger RR, Haughey HM, Wilkins DG, Gibb JW, Hanson GR, Fleckenstein AE. Methamphetamineinduced rapid decrease in dopamine transporter function: Role of dopamine and hyperthermia. $\mathrm{J}$ Pharmacol Exp Ther. 2000; 295:1077-85. [PubMed: 11082443]

Ojeda S, Andrews W, Advis J, White S. Recent advances in the endocrinology of puberty. Endocrine Rev. 1980; 1:228-257. [PubMed: 6112144]

Ojeda, S.; Ubananski, H. Puberty in the rat. In: Knovil, E.; Neill, J., editors. The Physiology of Reproduction. Vol. 2. Raven Press; NY: 1994. p. 363-397.

O’Neil ML, Kuczenski R, Segal DS, Cho AK, Lacan G, Melega WP. Escalating dose pretreatment induces pharmacodynamic and not pharmacokinetic tolerance to a subsequent high-dose methamphetamine binge. Synapse. 2006; 60(6):465-73. [PubMed: 16897726]

Pu C, Vorhees CV. Developmental dissociation of methamphetamine-induced depletion of dopaminergic terminals and astrocyte reaction in rat striatum. Brain Res Dev Brain Res. 1993; 72:325-328.

Riddle EL, Kokoshka JM, Wilkins DG, Hanson GR, Fleckenstein AE. Tolerance to the neurotoxic effects of methamphetamine in young rats. Eur J Pharmacol. 2002; 435(2-3):181-5. [PubMed: $11821024]$

Sandoval V, Riddle EL, Hanson GR, Fleckenstein AE. Methylphenidate redistributes vesicular monoamine transporter-2: role of dopamine receptors. J Neurosci. 2002; 22:8705-10. [PubMed: 12351745]

Scott JC, Woods SP, Matt GE, Meyer RA, Heaton RK, Atkinson JH, Grant I. Neurocognitive effects of methamphetamine: a critical review and meta-analysis. Neuropsychol Rev. 2007; 17:275-97. [PubMed: 17694436]

Sekine Y, Iyo M, Ouchi Y, Matsunaga T, Tsukada H, Okada H, Yoshikawa E, Futatsubashi M, Takei $\mathrm{N}$, Mori N. Methamphetamine-related psychiatric symptoms and reduced brain dopamine transporters studied with PET. Am J Psych. 2001; 158:1206-1214.

Sharma HS, Kiyatkin EA. Rapid morphological brain abnormalities during acute methamphetamine intoxication in the rat: an experimental study using light and electron microscopy. J Chem Neuroanat. 2009; 37(1):18-32. [PubMed: 18773954]

Shioda K, Nisijima K, Yoshino T, Kato S. Effect of risperidone on acute methamphetamine-induced hyperthermia in rats. Drug Alcohol Depend. 2010 Epub ahead of print.

Simon SL, Domier C, Carnell J, Brethen P, Rawson R, Ling W. Cognitive impairment in individuals currently using methamphetamine. Am J Addiction. 2000; 9:222-231.

Thomas DM, Francescutti-Verbeem DM, Kuhn DM. The newly synthesized pool of dopamine determines the severity of methamphetamine-induced neurotoxicity. J Neurochem. 2008; 105:605-16. [PubMed: 18088364]

Truong JG, Wilkins DG, Baudys J, Crouch DJ, Johnson-Davis KL, Gibb JW, Hanson GR, Fleckenstein AE. Age-dependent methamphetamine-induced alterations in vesicular monoamine transporter-2 function: implications for neurotoxicity. J Pharmacol Exp Ther. 2005; 314:1087-92. [PubMed: 15901804]

Volkow ND, Chang L, Wang G-J, Fowler JS, Leonido-Yee M, Franceschi D, Sedler MJ, Gatley SJ, Hitzemann R, Ding YS, Logan J, Wong C, Miller EN. Association of dopamine transporter reduction with psychomotor impairment in methamphetamine abusers. Am J Psychiatry. 2001; 158:377-382. [PubMed: 11229977]

Vorhees CV, Reed TM, Morford LL, Fukumura M, Wood SL, Brown CA, Skelton MR, McCrea AE, Rock SL, Williams MT. Periadolescent rats (P41-50) exhibit increased susceptibility to Dmethamphetamine-induced long-term spatial and sequential learning deficits compared to juvenile (P21-30 or P31-40) or adult rats (P51-60). Neurotoxicol Teratol. 2005; 27:117-134. [PubMed: 15681126]

Wagner GC, Lucot JB, Schuster CR, Seiden LS. Alpha-methyltyrosine attenuates and reserpine increases methamphetamine-induced neuronal changes. Brain Res. 1983; 270:285-288. [PubMed: 6883096]

Wagner GC, Ricaurte GA, Seiden LS, Schuster CR, Miller RJ, Westley J. Long-lasting depletions of striatal dopamine and loss of dopamine uptake sites following repeated administration of methamphetamine. Brain Res. 1980; 181:151-160. [PubMed: 7350950] 
Wilson JM, Kalasinsky KS, Levey AI, Bergeron C, Reiber G, Anthony RM, Schmunk GA, Shannak K, Haycock JW, Kish SJ. Striatal dopamine nerve terminal markers in human, chronic methamphetamine users. Nat Med. 1996; 2:699-703. [PubMed: 8640565]

Woolverton WL, Ricaurte GA, Forno L, Seiden LS. Long-term effects of chronic methamphetamine administration in rhesus monkeys. Brain Res. 1989; 486:73-78. [PubMed: 2720435]

Yamamoto BK, Bankson MG. Amphetamine neurotoxicity: cause and consequence of oxidative stress. Crit Rev Neurobiol. 2005; 17:87-117. [PubMed: 16808729] 
A

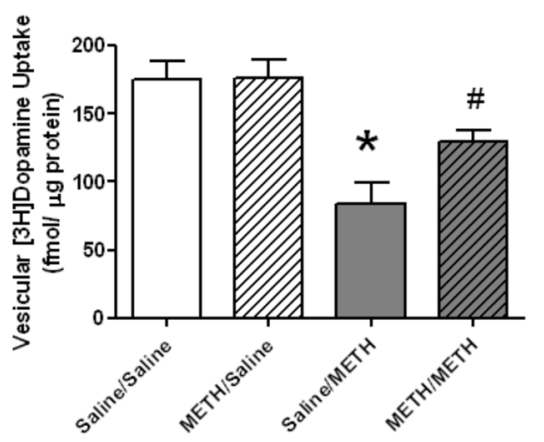

C

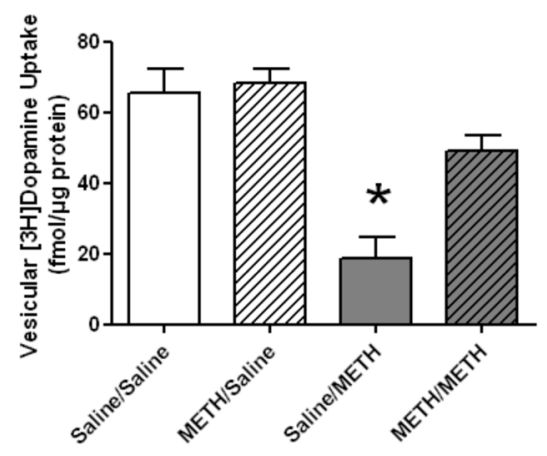

B

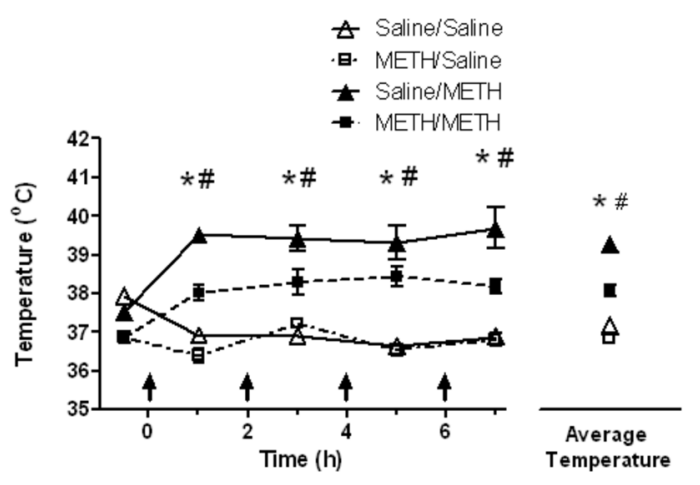

D

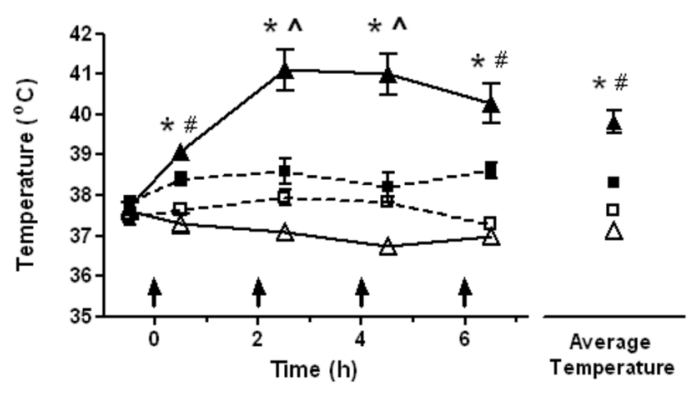

Figure 1.

Rats were designated to receive a single injection of METH $(7.5 \mathrm{mg} / \mathrm{kg}$, s.c.) or saline vehicle $(1 \mathrm{ml} / \mathrm{kg}$, s.c.) on two consecutive days weekly for six consecutive weeks. One week after the final treatment (i.e., at a time at which rats had attained the age PND90), rats received four injections of METH $(7.5 \mathrm{mg} / \mathrm{kg} /$ injection, s.c., 2-h intervals as indicated by the arrows) or saline vehicle (1 ml/kg, s.c.). Rats were decapitated 1 hour (panels A and B) or 7 days (panels $\mathrm{C}$ and D) later. Vesicular dopamine uptake deficits and core body temperatures were significantly attenuated in rats given METH during development when a four-injection METH challenge was given. *Values for saline pretreated/METH challenged (saline/ METH) rats are significantly different from METH pretreated/saline challenged controls (METH/saline) and saline pretreated/saline challenged controls (saline/saline; $p<0.05$ ). \#Values for METH pretreated/METH-challenged (METH/METH) rats significantly differ from saline challenged controls (METH/saline and saline/saline; $\mathrm{p}<0.05)$. ${ }^{\wedge}$ Values for the METH/METH group significantly differ from the saline/METH and saline/saline groups ( $\mathrm{p}$ $<0.05)$. Data are expressed as means \pm SEM. 
A

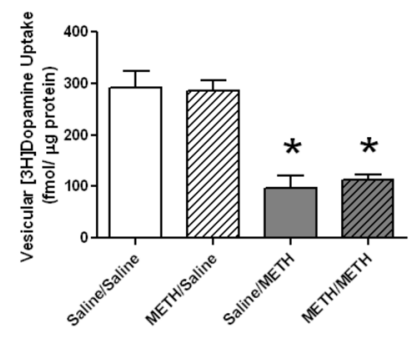

C

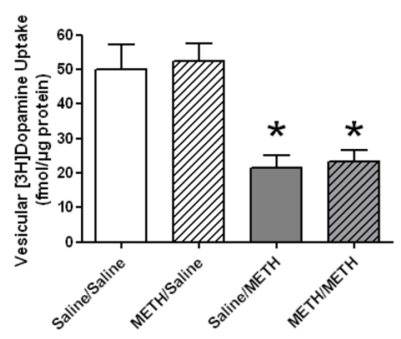

B

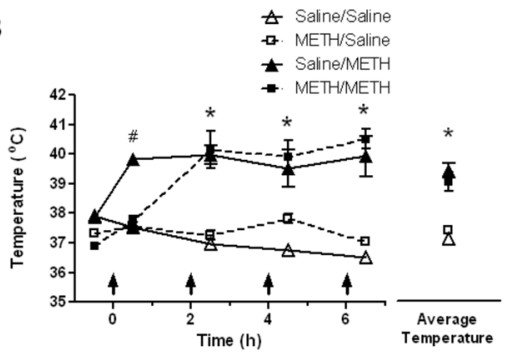

D

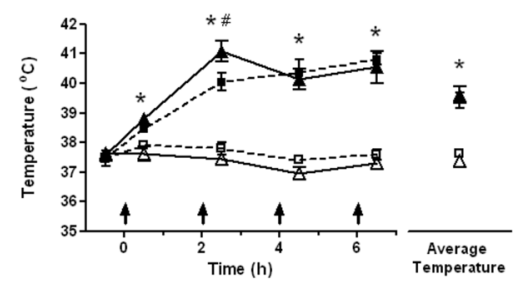

Figure 2.

Rats were treated identically as described in the legend to Fig. 1 except that rats received the 4-injection METH regimen in a warm environment $\left(25^{\circ} \mathrm{C}\right)$. Rats were decapitated 1 hour (panels A and B) or 7 days (panels $\mathrm{C}$ and $\mathrm{D}$ ) later. The warm environment resulted in similar core body temperatures in rats given the 4-injection METH regimen regardless of the pretreatment given during development (panels B and D) and similar reductions in vesicular uptake (panels A and C). *Values for saline pretreated/METH challenged (saline/METH) and METH pretreated/METH challenged (METH/METH) rats are significantly different from METH pretreated/saline challenged controls (METH/saline) and saline pretreated/ saline challenged controls (saline/saline; $\mathrm{p}<0.05$ ). \#Values for the saline/METH group significantly differ from all other groups $(\mathrm{p}<0.05)$. Data are expressed as means \pm SEM. 